\title{
Pricing and Logistics Service Level Decisions in Retailer's Dual-Channel Cooperation
}

\author{
Tianjiao Zhang* and Jie Xu
}

School of Economics and Management, Beijing Jiaotong University, 100044, Haidian, Beijing, China

\begin{abstract}
Based on the cooperation between retailer and third-party network platform, this article used consumer valuation model considering sale price and logistics factors. It calculated the optimal sale price and logistics service level in both traditional channel and internet channel and then get the maximal profit. By discussing the range of wholesale price, it analyzed the respective profits of retailer and third-party network platform. And then, it made sensitivity analysis of profits and sales quantities by using MATLAB software. This article concludes the cooperative conditions under centralized decision making situation and provides guidelines for retailers to develop dual-channel cooperation.
\end{abstract}

Keywords: Dual-channel, logistics service level, price, retailer, third-party network platform.

\section{INTRODUCTION}

The development of e-commerce has bought great impact to traditional retail industry and retailers started to find other ways besides real stores. Retailer's dual-channel cooperation has gained a lot of attentions.

The related studies of dual-channel focused more on the dual-channel supply chains of the manufacturer. Huang (2012) studied pricing and production decisions of the single-manufacturer and single- retailer due to the demand changes [1]. Hua (2010) mentioned that not only the price of the product affected the demand, the service quality and the lead time also played an important role [2]. Takahashi (2011) considered the setup costs in terms of the number of production and delivery setups [3].Yan (2011) focused on the roles played by differentiated branding and profit sharing in a multi-channel manufacturer-retailer supply chain [4]. Liu (2010) studied the optimal strategy of dual-channel supply chain under symmetrical information environment [5].

In terms of pricing and service level of the dual-channel, Kevin Chiang (2003) defined the demand function of dualchannel [6]. Xu (2012) considered the delivery lead time's influence on decision [7]. Dan (2012) studied the service factor for retailer when making price decisions [8]. Chang HsinHsin (2011) described customer perceived value's influence on customer loyalty in the e-commerce environment [9]. Svein (2011) discussed product differentiation and cooperative governance. He said that it is a big challenge for selling agricultural products when facing with differentiated demands [10].

Above all, this article is written from the perspective of retailers. It is based on the cooperation of retailers and

third-party network platform to make optimal centralized decisions of pricing and logistics service level online and offline. At the same time, to discuss the optimal allocation of profits under the circumstance of dual-channel.

\section{DECISION MAKING AND PROFIT DISTRIBU- TION}

\subsection{Problem Description}

By implementing dual-channel, retailer and the network platform have to decide the prices and logistics service in centralized decision making in order to get maximal profits. Then retailer should analyze the wholesale price to distribute profit. The product's price in traditional channel and the wholesale price are decided by retailer. The network platform decides the selling price on the internet and logistics service level. The relationship of retailer's dual-channel is as Fig. (1) shows:

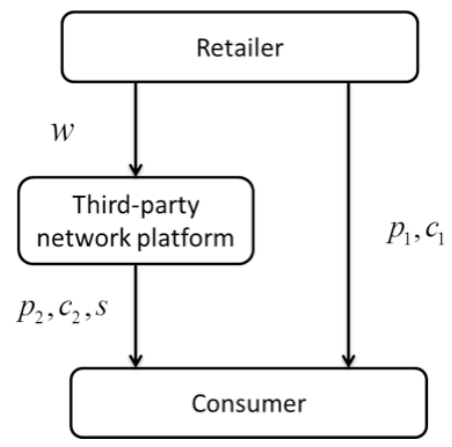

Fig. (1). Retailer's dual-channel.

We know that price and service level can affect final profit in different ways. In terms of price, prices in the two channels will influence online and offline demand and profit. In terms of logistics, the logistics service level is related to the online consumer valuation, which can affect demand 
directly and finally influence profit. The logistics cost is determined by the service level. The relationship of these factors is shown in Fig. (2).

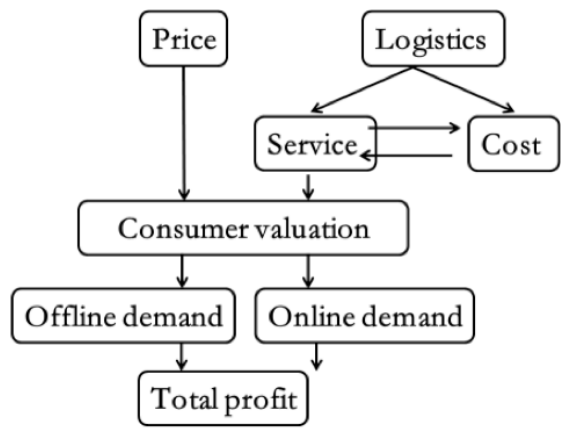

Fig. (2). Relationship of factors.

\subsection{Basic Assumptions}

For the requirement of quantitative analysis, there are some basic assumptions:

- The article focus on the cooperation of single retail and single third-party network platform selling one product.

- Assume that the demand is unit demand, consumer can buy one or zero unit of product.

- Retailer and network platform bear the unit selling cost respectively.

- Assume that the logistics service level is quadratic function of logistics cost.

\subsection{Variables and Parameters}

Decision variables : $p_{1}$ : sale price on traditional channel; $p_{2}$ : sale price on internet channel;w: wholesale price for network platform, $0 \leq \mathrm{w} \leq p_{1}, 0 \leq \mathrm{w} \leq p_{2}$; : logistics service level, $\mathrm{s} \geq 0$.

Parameters: $c_{1}, c_{2}$ : unit selling cost in traditional and internet channel; $\beta$ : consumers' sensitivity to service, $0 \leq \beta \leq$ $1 ; \theta$ : acceptance of internet, $0 \leq \theta \leq 1 ; \sigma$ : logistics service level influence coefficient of cost, $0 \leq \sigma \leq 1$; : consumer valuation, $0 \leq \mathrm{v} \leq 1$, according to Chiang,W.K.[6], it is uniformly distributed from 0 to $1 . Q_{1}, Q_{2}$ : sale quantities in traditional and internet channel. $\pi_{r}, \pi_{e}$ : profits of retailer and network platform.

\subsection{The Building Solving and Analysis of the Model}

\subsubsection{The Building of the Function of Requirement}

We assume that the consumption value of the product is determined by both the price and logistics service level.

The product has the consumption value ofv. Consumers who buy product from the stores can only be affected by price, so the net valuation is defined as $U_{1}=v-p_{1}$.If $U_{1} \geq 0$, consumers will buy the product through traditional channel. Whose valuation satisfies $v-p_{1}<0$ will not buy. So we can get the marginal valuation $\hat{v}_{1}=p_{1}$. Consumers who buy products through the internet will have a virtual inspection of the product which may cause the product value $\theta v$. The parameter $\theta$ is called the customer acceptance of the internet. Also, buying from the internet will induce logistics activities, which will affect the consumption value. So the valuation is defined as $U_{2}=\theta v-p_{2}+\beta s$. The parameter $\beta$ shows consumers' sensitivity to the logistics service level. Also, we can easily get the marginal valuation $\hat{v}_{2}=\frac{p_{2}-\beta s}{\theta}$. When there are two channels, consumers will choose the channel which its valuation is greater. So we can get the marginal valuation $\hat{v}_{12}=\frac{p_{1}-p_{2}+\beta s}{1-\theta}$. If $v \geq \hat{v}_{12}$, the consumers are preferred to the traditional channel.

(1) If $\hat{v}_{1}<\hat{v}_{2}$, $\operatorname{so} p_{1}<\frac{p_{2}-\beta s}{\theta}$, and $\hat{v}_{12}=\frac{\hat{v}_{1}-\theta \hat{v}_{2}}{1-\theta}<\frac{\hat{v}_{1}-\theta \hat{v}_{1}}{1-\theta}=$ $\hat{v}_{1}$, then $\hat{v}_{12}<\hat{v}_{1}<\hat{v}_{2}$. That is to say, consumers are only buying products from traditional channel and the requirement $Q_{1}=1-\hat{v}_{1}=1-p_{1}$.

(2) If $\hat{v}_{1}>\hat{v}_{2}, \quad \operatorname{so} p_{1}>\frac{p_{2}-\beta s}{\theta}$, and $\hat{v}_{12}=\frac{\hat{v}_{1}-\theta \hat{v}_{2}}{1-\theta}>\frac{\hat{v}_{1}-\theta \hat{v}_{1}}{1-\theta}=$ $\hat{v}_{1}$, then $1>\hat{v}_{12}>\hat{v}_{1}>\hat{v}_{2}$. The requirement in the traditional channel $Q_{1}=1-\hat{v}_{12}=1-\frac{p_{1}-p_{2}+\beta s}{1-\theta}$, the requirement in the internet channel $Q_{2}=\hat{v}_{12}-\hat{v}_{2}=$ $\frac{\theta p_{1}-p_{2}+\beta s}{\theta(1-\theta)}$.

So, the requirement function can be defined as: $\left(Q_{1}, Q_{2}\right)=$

$$
\left\{\begin{array}{c}
\left(1-p_{1}, 0\right), p_{1}<\frac{p_{2}-\beta s}{\theta} \\
\left(1-\frac{p_{1}-p_{2}+\beta s}{1-\theta}, \frac{\theta p_{1}-p_{2}+\beta s}{\theta(1-\theta)}\right), \frac{p_{2}-\beta s}{\theta}<p_{1}<\frac{p_{1}-p_{2}+\beta s}{1-\theta}
\end{array}\right.
$$

\subsubsection{Profits under Centralized Decision Making}

Under this condition, the retailer and the network platform are regarded as a whole, the question is to solve the optimal profit of the whole system. So in this section, we only need to decide two sale prices and logistics service level. The wholesale price will be discussed later. The total profit $\pi=\left(p_{1}-c_{1}\right) Q_{1}+\left(p_{2}-c_{2}\right) Q_{2}-\frac{1}{2} \sigma s^{2}$.

(1) If $p_{1}<\frac{p_{2}-\beta s}{\theta}$, consumers will only buy products from traditional channel. The profit function can be written $\operatorname{ast}_{1}=\left(p_{1}-c_{1}\right) Q_{1}=\left(p_{1}-c_{1}\right)\left(1-p_{1}\right)$. Let $\frac{\partial \pi_{1}}{\partial p_{1}}=$ 0 ,getting that $p_{1}{ }^{*}=\frac{1+c_{1}}{2}$. So $Q_{1}{ }^{*}=\frac{1-c_{1}}{2}$ and $\pi_{1}{ }^{*}=$ $\frac{\left(1-c_{1}\right)^{2}}{4}$.

(2) If $\frac{p_{2}-\beta s}{\theta}<p_{1}<\frac{p_{1}-p_{2}+\beta s}{1-\theta}$, so $\theta p_{1}+\beta s-p_{2}>0$. Consumers can buy products from either traditional channel or internet channel. The total profit function can be written as $\pi_{2}=\left(p_{1}-c_{1}\right)\left(1-\frac{p_{1}-p_{2}+\beta s}{1-\theta}\right)+\left(p_{2}-\right.$ $\left.c_{2}\right) \frac{\theta p_{1}-p_{2}+\beta s}{\theta(1-\theta)}-\frac{1}{2} \sigma s^{2}$.

The optimal solution exists when Hessian matrix is negative definite. Partial derivative of $p_{1}, p_{2}, s$, we can get that $\mathrm{H}=\left[\begin{array}{ccc}-\frac{2}{1-\theta} & \frac{2}{1-\theta} & \frac{-\beta}{1-\theta} \\ \frac{2}{1-\theta} & \frac{-2}{1-\theta}-\frac{2}{\theta} & \frac{2 \beta}{1-\theta} \\ \frac{-\beta}{1-\theta} & \frac{\beta}{1-\theta}+\frac{\beta}{\theta} & -\sigma\end{array}\right]$, let $|H|<0$, getting that 
$\beta^{2}-\sigma(1-\theta)<0$. And the optimal prices and service level are:

$p_{1}^{*}=\frac{1+c_{1}}{2}$

$p_{2}{ }^{*}=\frac{\theta+c_{2}}{2}+\frac{\beta^{2}\left(\theta c_{1}-c_{2}\right)}{2\left[2 \theta \sigma(1-\theta)-\beta^{2}\right]}$

$S^{*}=\frac{\beta\left(\theta c_{1}-c_{2}\right)}{2 \theta \sigma(1-\theta)-\beta^{2}}$.

$Q_{1}^{*}=\frac{1}{2}+\frac{\beta^{2} c_{1}-2 \theta \sigma\left(c_{1}-c_{2}\right)}{2\left[2 \theta \sigma(1-\theta)-\beta^{2}\right]}$

$Q_{2}^{*}=\frac{\sigma\left(\theta c_{1}-c_{2}\right)}{2 \theta \sigma(1-\theta)-\beta^{2}}$

$\pi_{2}^{*}=\frac{\left(1-c_{1}\right)^{2}}{4}+\frac{\sigma\left(\theta c_{1}-c_{2}\right)^{2}}{2\left[2 \theta \sigma(1-\theta)-\beta^{2}\right]}$

Then we can compare the two profits. In order to simplify the calculation, lettingM $=2 \theta \sigma(1-\theta)-\beta^{2}$. First, in the situation (2), the solution satisfies $\theta p_{1}+\beta s-p_{2}>0$. So we can get $2 \theta \sigma(1-\theta) \frac{\theta c_{1}-c_{2}}{M}>0$, because that $2 \theta \sigma(1-\theta)>$ 0 , so $\frac{\theta c_{1}-c_{2}}{M}>0$.

Compare the profits: $\pi_{2}{ }^{*}-\pi_{1}{ }^{*}=\frac{\sigma\left(\theta c_{1}-c_{2}\right)^{2}}{2 M}=$ $\frac{\theta c_{1}-c_{2}}{\mathrm{M}}\left(\theta c_{1}-c_{2}\right)$. Because that $\sigma \frac{\theta c_{1}-c_{2}}{M}>0$, then $\pi_{2}{ }^{*}-\pi_{1}{ }^{*}\left\{\begin{array}{l}\geq 0, \theta c_{1}-c_{2} \geq 0 \\ \leq 0, \theta c_{1}-c_{2}<0\end{array}\right.$. We can conclude that when $\theta \geq \frac{c_{2}}{c_{1}}$, dual-channel can bring more profits. If $\theta<\frac{c_{2}}{c_{1}}$, retailer should better not cooperate with the network platform. He can get more profit by only using traditional channel.

\subsubsection{Wholesale Price Deciding and Profit Distribution}

Under the condition $\theta \geq \frac{c_{2}}{c_{1}}$, the two parties can get maximal profit together. Then they should distribute revenue. It is easy to inference that wholesale price is the key to the distribution rule. High wholesale price will frustrate the enthusiasm of network platform while retailer won't get enough profit if the wholesale price is low. Considering wholesale price, the profit functions are:

$\pi_{r}=\left(p_{1}-c_{1}\right) Q_{1}+w Q_{2}=\frac{\left(1-c_{1}\right)^{2}}{4}+\frac{\sigma\left(\theta c_{1}-c_{2}\right)\left(2 w-\theta+\theta c_{1}\right)}{2 M}(9)$

$\pi_{e}=\left(p_{2}-c_{2}-w\right) Q_{2}-\frac{1}{2} \sigma S^{2}=\frac{\sigma\left(\theta c_{1}-c_{2}\right)\left(-2 w+\theta-c_{2}\right)}{2 M}(10)$

(1) If retailer decides to give up parts of profit in order to gain some sales, there exists $\pi_{r}=\pi_{1}{ }^{*}$, then $2 w-\theta+$ $\theta c_{1}=0$, getting that $\mathrm{w}=\frac{\theta\left(1-c_{1}\right)}{2}$. Then network platform can get his maximal profit $\pi_{e}=\frac{\sigma\left(\theta c_{1}-c_{2}\right)^{2}}{2 M}$.

(2) If retailer wants more profit through cooperation and network platform can't loss, we can get the constraints: $\left\{\begin{array}{c}\pi_{r}>\pi_{1}{ }^{*} \\ \pi_{e}>0\end{array}\right.$, under this condition we can get that $\frac{\theta\left(1-c_{1}\right)}{2}<$ $w<\frac{\theta-c_{2}}{2}$, during which retailer and platform can both benefit.

(3) If retailer wants his maximal profit, supposing that he wants to increase apercentage of original revenue. Then we get function and constraint:

$$
\begin{gathered}
\max \pi_{r}=\max \frac{\left(1-c_{1}\right)^{2}}{4}+\frac{\sigma\left(\theta c_{1}-c_{2}\right)\left(2 w-\theta+\theta c_{1}\right)}{2 M} \\
\text { s. t. } \pi_{e}=\frac{\sigma\left(\theta c_{1}-c_{2}\right)^{2}}{2 M}-\alpha \frac{\left(1-c_{1}\right)^{2}}{4} \geq 0
\end{gathered}
$$

Solving this problem we can get that $\alpha \leq \frac{2 \sigma}{M}\left(\frac{\theta c_{1}-c_{2}}{1-c_{1}}\right)^{2}$ and the maximal profit of retailer is $\pi_{r}=\pi_{2}{ }^{*}=\frac{\left(1-c_{1}\right)^{2}}{4}+$ $\frac{\sigma\left(\theta c_{1}-c_{2}\right)^{2}}{2 M}$ when $\mathrm{w}=\frac{\theta-c_{2}}{2}$.

\section{SENSITIVITY ANALYSIS}

\subsection{Sensitivity Analysis of Profits}

We get wholesale price from above which varies from $\frac{\theta\left(1-c_{1}\right)}{2}$ to $\frac{\theta-c_{2}}{2}$. To calculate simply, we supposing an average $\mathrm{w}=\frac{2 \theta-\theta c_{1}-c_{2}}{3}$. So equation (9) and (10) can be written as:

$$
\begin{gathered}
\pi_{r}=\frac{\left(1-c_{1}\right)^{2}}{4}+\frac{\sigma\left(\theta c_{1}-c_{2}\right)\left(\theta+\theta c_{1}-2 c_{2}\right)}{6\left[2 \theta \sigma(1-\theta)-\beta^{2}\right]} \\
\pi_{e}=\frac{\sigma\left(\theta c_{1}-c_{2}\right)\left(2 \theta c_{1}-c_{2}-\theta\right)}{6\left[2 \theta \sigma(1-\theta)-\beta^{2}\right]}
\end{gathered}
$$

We can see from the function that the two profits are influenced by $c_{1}, c_{2}, \theta, \beta, \sigma$. Supposing that the unit cost of sales $c_{1}, c_{2}$ and the logistics service level influence coefficient of cost $\sigma$ can be predicted in advance. So we only analyze how the acceptance of internet $\theta$ and the consumers' sensitivity to logistics service $\beta$ affect the profits.

Supposing that $c_{1}=0.8, c_{2}=0.2, \sigma=0.5$. Because of $\theta \geq \frac{c_{2}}{c_{1}}, \theta \geq 0.25$. Fig. (3). shows how $\theta$ affects profits when $\beta=0.3$ and $\beta=0.6$.

We can see from Fig. (3) that both retailer and network platform's profits are greatly affected by $\theta$. When consumers are not really sensitive to service $(\beta=0.3)$, the profits increase as $\theta$ grows and the growth rate is rather high. When the consumers are not sensitive to service, the platform can get more revenue without paying on service inputs. However, when consumers are sensitive to service $(\beta=0.6)$, platform have to pay more service cost which may declines the profits. So we conclude that it is benefit for retailer and platform to increase the acceptance of internet when facing serviceinsensitive consumers.

Then Fig. (4). shows how $\beta$ affects profits when $\theta=$ $0.4,0.6$.

Fig. (4) shows that when consumer's sensitivity to service increases in certain range $(\beta<0.5)$, the two profits grow accordingly. Once $\beta$ goes over the range, there is nearly no profits. Also, we can see that bigger acceptance of internet will bring more profits when consumers' sensitivity to service is fixed. This conclusion is consistent with the above one.

\subsection{Sensitivity Analysis of Sales Quantity}

The sales quantities of the two channels are shown in equation (5) and (6). Same as profits, quantities are affected 


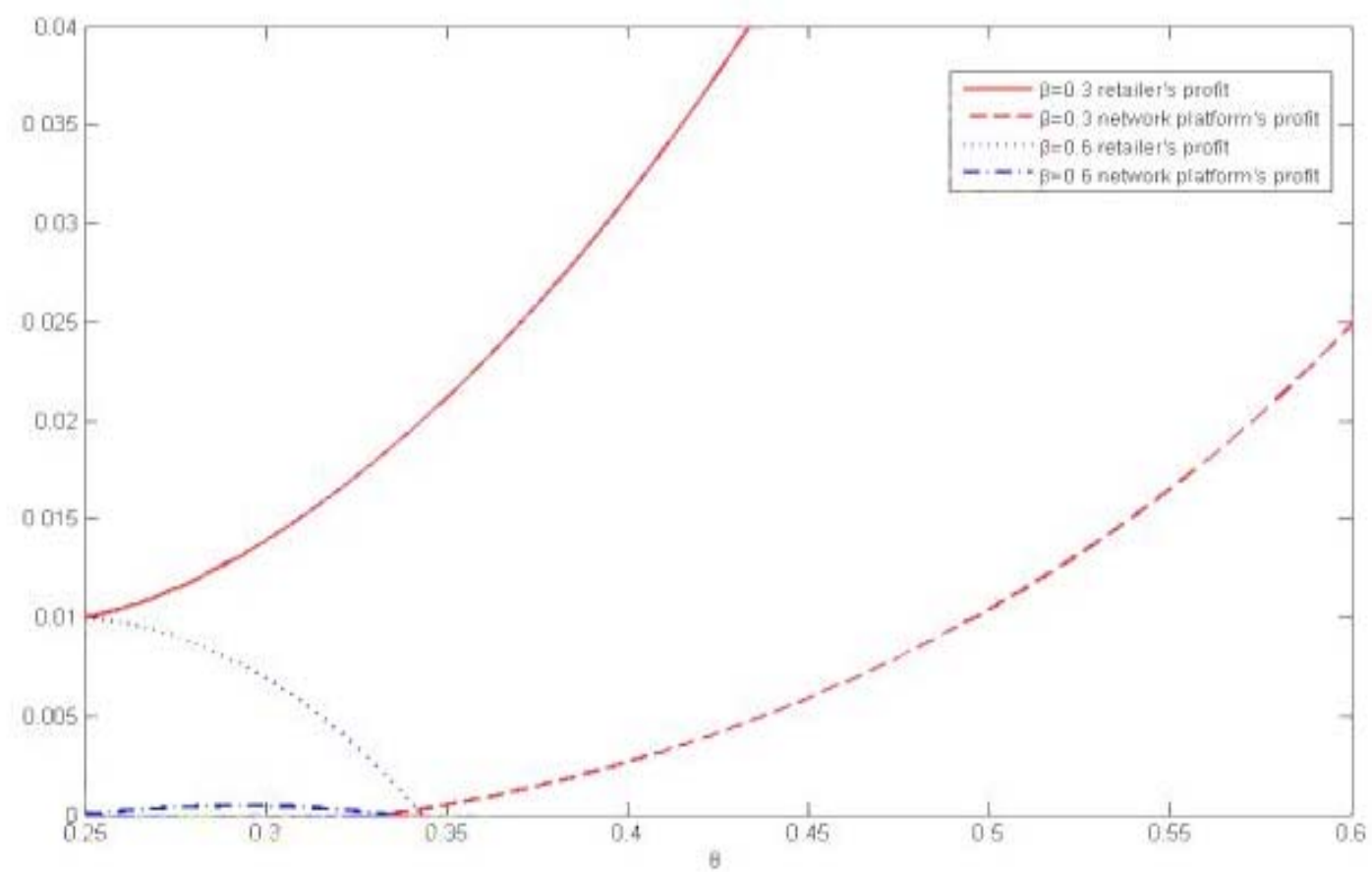

Fig. (3). $\boldsymbol{\theta}$ Affects profits.

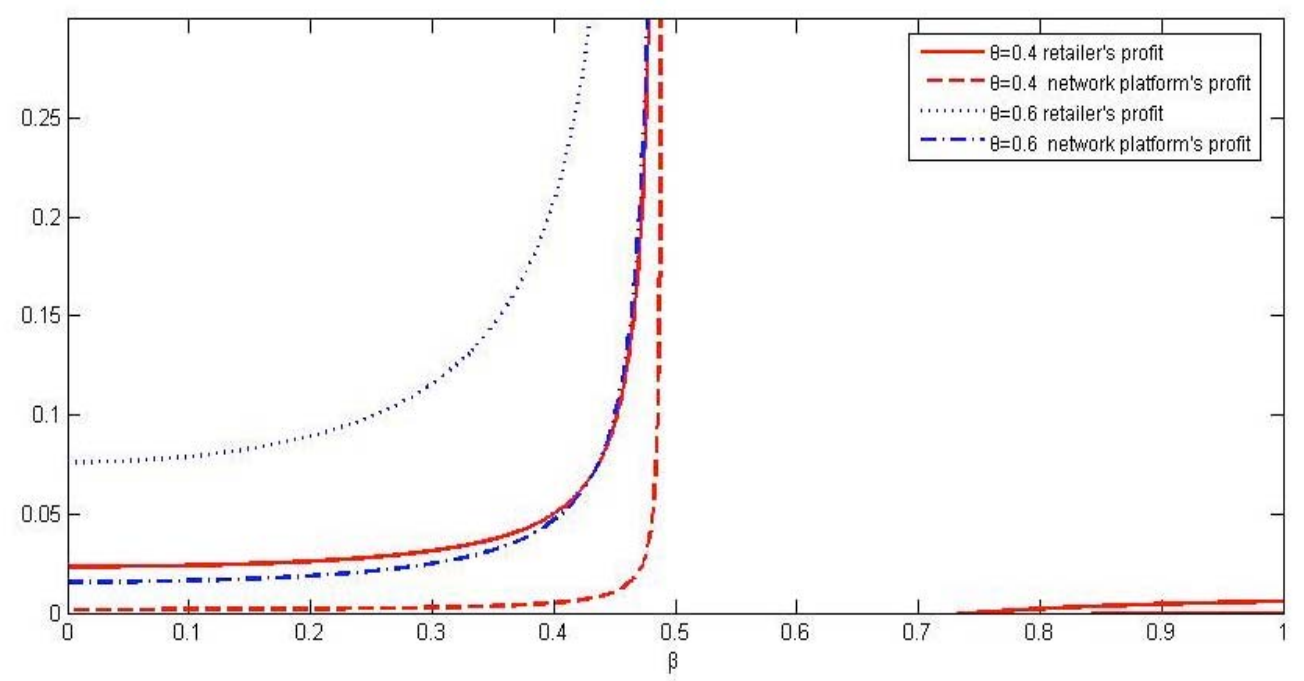

Fig. (4). $\boldsymbol{\beta}$ Affects profits.

by the five factors. We only analyze how the acceptance of internet and the consumers' sensitivity to logistics service affect the sales quantities. Also supposing $c_{1}=0.8, c_{2}=$ $0.2, \sigma=0.5$, Fig. (5) show sales quantities are affected by acceptance of internet when $\beta=0.3$ and $\beta=0.6$.

When $\theta \geq 0.25$ and consumers' sensitivity to service level is low ( $\beta=0.3)$, the sales quantities of internet channel grow as the acceptance of internet increases, while the sales quantity of traditional channel declines. The reason is that when consumers are insensitive to service, they don't care the channel when they choose. So as the acceptance of internet grows, more people tend to buy through the internet. However, when consumers are sensitive to service, they may complain when the service level can't satisfy them, which lead to the decline of internet channel's sales quantities.
Fig. (6) shows how sales quantitiesare affected by consumers' sensitivity of service when $\theta=0.3$ and $\theta=0.6$.

This figure shows that when the sensitivity grows below a certain level, the quantities in the internet channel will increase, while the quantitiesin the traditional channel decreases to a low level. It reflects consumers want to experience the online service. And the quantities grow as the acceptance of internet increases. However, if consumers are too sensitive to service, the present level can't satisfy them. And quantities will decrease.

\section{CONCLUSION}

Through the analysis, can get the following conclusions: Firstly, retailer can get more profit by cooperating with third- 


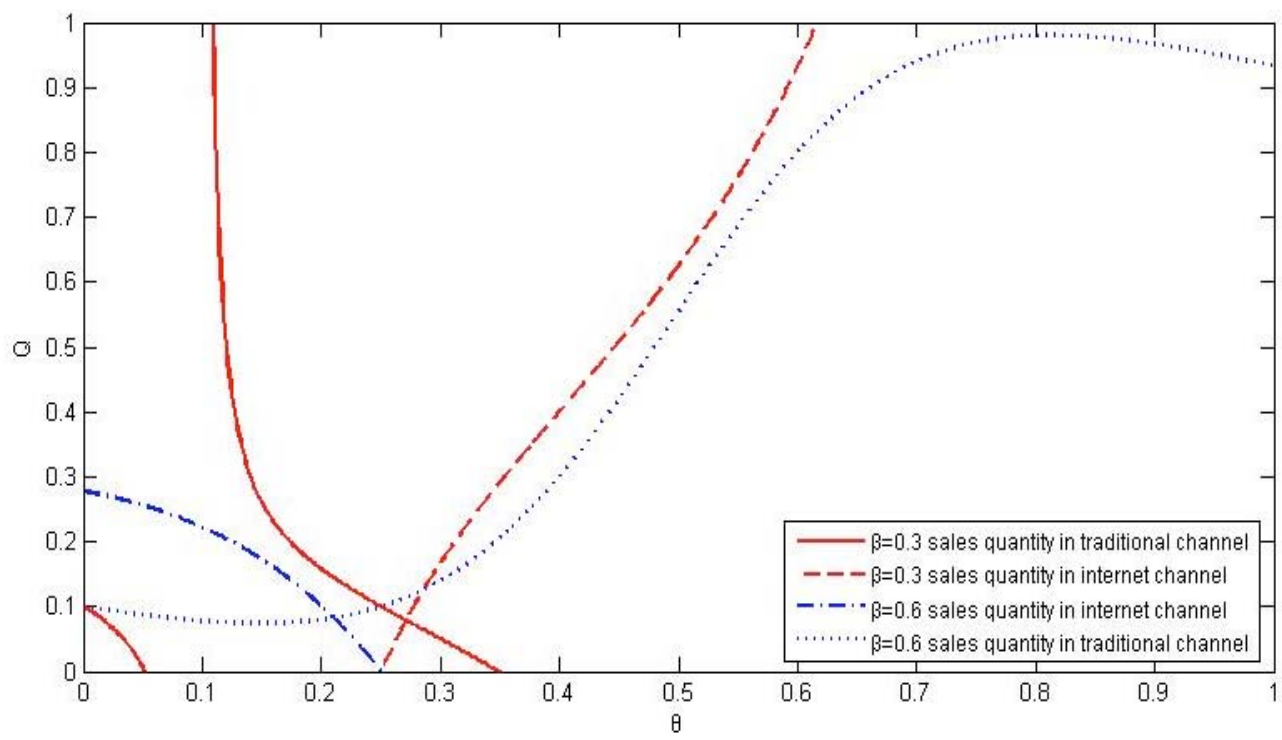

Fig. (5). $\boldsymbol{\theta}$ Affects quantities.

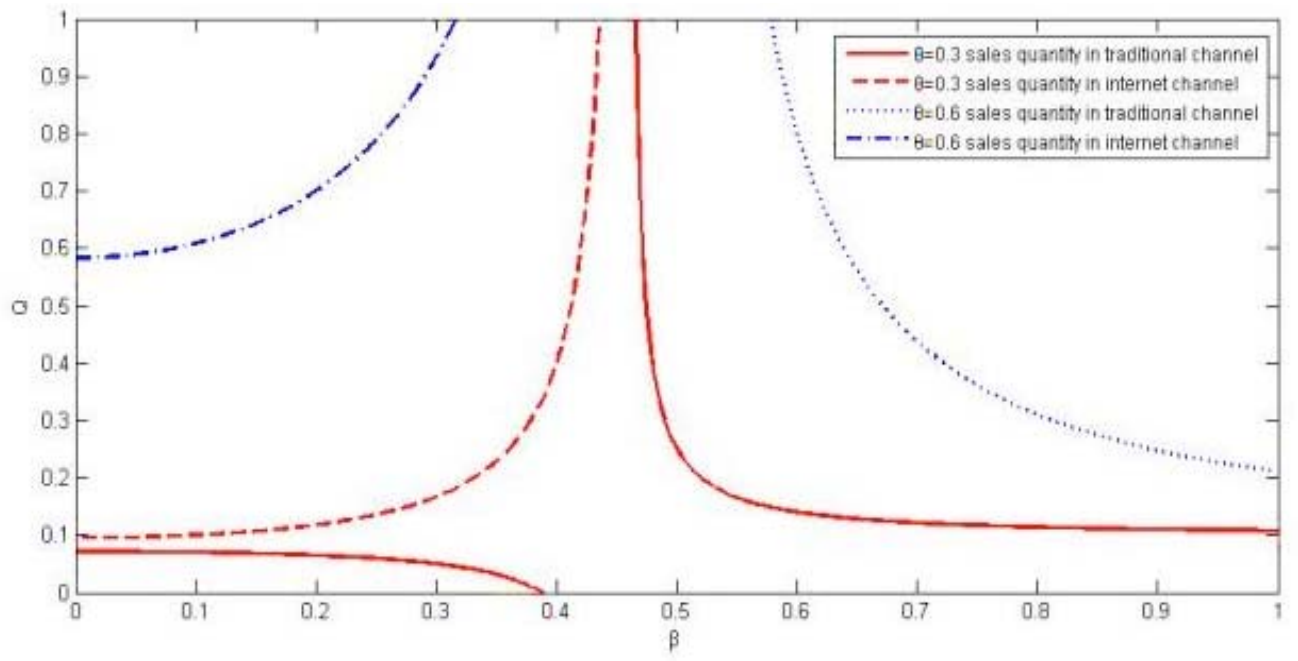

Fig. (6). $\boldsymbol{\beta}$ Affects quantities.

party network platform when the acceptance of internet is bigger than the unit selling cost ratio of internet channel and traditional channel. Secondly, when the cooperation reaches, the optimal sale prices and logistics service level are decided by the unit selling costs, the logistics service level influence coefficient of cost, the acceptance of internet and the consumers' sensitivity to logistics service.Thirdly, the wholesale price should satisfy $\frac{\theta\left(1-c_{1}\right)}{2}<w<\frac{\theta-c_{2}}{2}$. And network platform can get optimal profitwhenw $=\frac{\theta\left(1-c_{1}\right)}{2}$; retailer benefits mostwhen $\mathrm{w}=\frac{\theta-c_{2}}{2}$. Finally, retailer and platform should choose consumers who are not sensitive to service when the price is fixed and try to expand the acceptance of internet.

This article analyzes the cooperation condition of retailer and third-party network platform, makes decisions about the optimal prices and logistics service level and discusses the distribution of the maximum common profit. It is hoped to offer some useful references for small retailers to develop dual-channel cooperation. The article still has some shortcomings such as not considering the situation of decentralized decision-making and the service's impact on product price.It will be improved in the further study.

\section{CONFLICT OF INTEREST}

The authors confirm that this article content has no conflict of interest.

\section{ACKNOWLEDGEMENTS}

Declared none.

\section{REFERENCES}

[1] S. Huang, C. Yang, and X. Zhang, "Pricing and production decisions in dual-channel supply chains with demand disruptions,"Computers \& Industrial Engineering, vol. 62, no. 1, 
pp. 70-83, 2012

G. Hua, S. Wang, and T.C.E. Cheng, "Price and lead time decisions in dual-channel supply chains,"European Journal of Operational Research, vol. 205, no. 1, pp. 113-126, 2010.

[3] K. Takahashi, T. Aoi, D. Hirotani, and K. Morikawa, "Inventory control in a two-echelon dual-channel supply chain with setup of production and delivery,"International Journal of Production Economics, Volume 133, Issue 1, September 2011, Pages 403-415, ISSN 0925-5273.

[4] Ruiliang Yan, "Managing channel coordination in a multi-channel manufacturer-retailer supply chain,"Industrial Marketing Management, vol. 40, no. 4, pp. 636-642, 2011.

[5] B. Liu, X. Ma, and R. Zhang, "Joint decision on pricing and advertising for competing retailers under emergency purchasing," Economic Modelling, vol. 39, pp. 257-264, 2014.

[6] W. K. Chiang, D. Chhajed, and J. D. Hess, "Direct marketing, indirect profits: Astrategic analysis of dual channel supply-chain design,"Management Science, vol. 49, no.1, pp. 1-20, 2003.

[7] X. He, Z. Z. Liu, and H. Z. Sheng, "A strategic analysis of dualchannel supply chain design with price and delivery lead time considerations,"International Journal of Production Economics, vol. 139, no. 2, pp. 654-663, 2012.

[8] B. Dan, G. Xu, and C. Liu, "Pricing policies in a dual-channel supply chain with retail services," International Journal of Production Economics, vol. 139, no. 1, pp. 312-320, 2012.

[9] H. H. Chang, and H. Wang, "The moderating effect of customer perceived value on online shopping behavior," Online Information Review vol.35, no.03, pp. 333-359, 2011.

[10] O. B. Svein, "Product differentiation and cooperative governance,"The Journal of Socio-Economics, vol. 40, no. 3, pp. 327-333, 2011.

Received: September 20, 2014

Revised: December 02, 2014

Accepted: December 31, 2014

(c) Zhang and Xu; Licensee Bentham Open.

This is an open access article licensed under the terms of the Creative Commons Attribution Non-Commercial License (http://creativecommons.org/licenses/by-nc/3.0/) which permits unrestricted, non-commercial use, distribution and reproduction in any medium, provided the work is properly cited. 